Paidéia, 2002, 12(22), 57-68

\title{
ADOLESCENTES DO SEXO FEMININO: FAMÍLIA, GRUPO DE PARES E RELAÇÕES AFETIVAS ${ }^{1}$
}

\author{
Geraldo Romanelli ${ }^{2}$ \\ FFCLRP - Universidade de São Paulo \\ Daniela Iglesias de Castro Prieto \\ IP - Universidade de Brasília
}

\begin{abstract}
RESUMO: A partir de pesquisa realizada com dez adolescentes do sexo feminino das camadas médias de Ribeirão Preto-SP, este trabalho analisa a constituição da identidade de gênero dessas adolescentes, suas relações com a família e com o grupo de pares e os vínculos afetivos com parceiros com os quais se fica e com namorados. A análise dos dados sugere que apesar da mudança nos padrões culturais e da nova posição assumida pelas mulheres, a constituição da identidade de gênero das adolescentes é marcada por ambigüidades em torno dos papéis femininos, o que contribui para que elas incorporem essas mesmas ambigüidades em sua conduta.
\end{abstract}

Palavras-chave: adolescente, família, identidade de gênero, grupo de pares, relações afetivas

\section{ADOLESCENT GIRLS: FAMILY, PEER GROUP AND AFFECTIVE RELATIONS}

ABSTRACT: On the basis of a survey of middle-class adolescent girls from Ribeirão Preto, the present study analyzes the constitution of gender identity of these girls, their relations with family and with peer group and the affective ties with occasional or steady boy friends. Analysis of the data suggests that, despite the change in cultural patterns and of the new positions of women, the constitution of gender identity of girls is marked by ambiguities about female roles, a fact that causes these girls to incorporate these same ambiguities into their behavior.

Key-words: adolescent, family, gender identity, peer group, affective relations

O objetivo deste trabalho é apreender algumas formas de sociabilidade de adolescentes do sexo feminino das camadas médias focalizando a análise em alguns aspectos da constituição da identidade de gênero, das relações com a família, da importância que o grupo de pares assume nesta fase de transição para a idade adulta, dos projetos de estudo associados à profissionalização, bem como dos vínculos afetivos vividos com parceiros com quem se fica e com namorados.

\footnotetext{
1 Artigo recebido para publicação em março de 2002; aceito em julho de 2002 .

2 Fndereço para correspondência: Geraldo Romanelli, Departamento de Psicologia e Educação, Faculdade de Filosofia, Ciências e Letras de Ribeirão Preto, USP, Av. Bandeirantes, 3900 , Monte Alegre, Ribeirão Preto, SP, Cep 14040-901, e-mail: geromane@ifclirp.usp.br
}

\section{A Constituição da Identidade de Gênero}

No artigo intitulado "Estrutura Familiar e Personalidade" Nancy Chodorow (1979) sugere que uma experiência discriminativa decisiva no desenvolvimento masculino e feminino resulta do fato de as mulheres serem as grandes responsáveis pelos cuidados com filhos pequenos. Nesse sentido, é preciso atentar para a importância fundamentai que a relação mãe-filha assume para as mulheres e os efeitos conscientes e inconscientes presentes na relação da genitora com filhos de ambos os sexos.

Diz-se que a criança inicia sua vida num estado de desamparo e necessita de cuidados para sobreviver, o que cria dependência e ligação com a mãe, que é geralmente a responsável pelo desempenho nessa tarefa. Outra característica da dependência infantil é a persistência da identificação primária com a mãe: a criança não diferencia a si 


\section{Geraldo Romanelli}

mesma dela; ao contrário, vivencia uma sensação de unidade. É provável que a maior responsabilidade materna na alimentação e no cuidado com o bebê prolongue e intensifique o período de identificação entre a criança e a mãe (Chodorow, 1979).

Nos primeiros anos de vida, a criança vive de modo intenso a dependência e a identificação com a figura materna. Gradualmente, a quebra ou o enfraquecimento dessa identificação acarreta o início do desenvolvimento de um sentimento individualizado do self e a redução da dependência materna. No decorrer desse processo, os problemas de separação e individuação são intensos, tanto para meninas quanto para meninos.

Chodorow sugere que, ao contrário do modelo psicanalítico tradicional, provavelmente a vivencia pré-edipiana é diferente para meninos e meninas. Como a mãe já foi menina, pode-se esperar que ela se identifique mais com as filhas. Ela tenderia, então, a tratar de modo diverso crianças de sexos diferentes.

Parece mais provável uma mãe se identificar com a filha do que com o filho, para vivenciar as experiências de sua filha (ou parte dessas) como dela própria (Chodorow, 1979, p. 69).

A formação da identidade de gênero feminina está integrada à relação de apego que a criança tem com a mãe e é fruto do processo de socialização, em que esta é a pessoa com quem a ela, de modo geral, mais convive, o que permite sejam transmitidos à filha exemplos, que irão configurar seu modo de ser e estabelecer a identificação da menina com a figura materna. $O$ relacionamento muito íntimo, mas que traz como resultado dificuldades no processo de individuação, ao mesmo tempo em que facilita a empatia e a sensibilidade para com o outro.

Os filhos do sexo masculino são vivenciados pela mãe como o contrário de si, o que faz com que eles as separarem de si mesmos, para se definirem como masculinos. Portanto, nesse caso a individuação é mais enfática e há uma fixação mais defensiva das fronteiras do ego. Separação e individuação achamse vinculadas à identidade de gênero masculina. Por isso, os homens tendem a se sentir ameaçados pela intimidade $\mathrm{e}$ a ter dificuldade com os relacionamentos
(Gilligan, s/d).

A análise de Chodorow (1979) sobre a formação da personalidade pode ser ampliada pelas contribuições de Gilligan (s/d) e de Lever (1976, apud Gilligan, s/d) sobre as diferenças nas atividades lúdicas de crianças. Segundo Lever, nas suas brincadeiras, os meninos aprendem tanto a independência quanto as qualificações organizacionais necessárias para coordenar atividades de grupos maiores e diversos de pessoas. Ao participarem de situações competitivas, regulamentadas e socialmente aprovadas, eles, de acordo com as regras do jogo, passam a enfrentar a competição de um modo relativamente direto. Já a atividade de brincar das meninas ocorre mais freqüentemente em grupos menores, mais íntimos. Tomando como referência os dados de Lever, Gilligan (s/d) mostra que as brincadeiras das meninas reproduzem o padrão social dos relacionamentos humanos primários, tendo uma organização mais cooperativa. Isso promove o desenvolvimento da empatia e da sensibilidade necessárias para assumir o lugar de alguém que é próximo, buscando entender o seu ponto de vista e possibilita a descoberta do outro como diferente de si. Lever (1976, apud Gilligan, s/d) ressalta que o jogo acába quando surge uma discussão nas brincadeiras femininas. Ou seja, ao invés de elaborar um sistema de regras para solucionar o conflito, as meninas subordinam a continuação do jogo à manutenção dos relacionamentos (Gilligan, s/d). Assimi, a sensibilidade no que tange às necessidades do outro e à responsabilidade em cuidar dele, levam as mulheres a embutir em seus julgamentos pontos de vista diferentes dos seus.

A proximidade entre mãe e filha, entre irmãs ou mulheres com ou sem vínculo de parentesco, cria uma teia de relações pautadas pela intimidade, pela possibilidade de expressão de emoções e sentimentos que são vividos e representados como exclusivamente femininos.

Ao lado desse universo de intimidade feminina, o mundo masculino é marcado pelo distanciamento promovido pelo processo de socialização, reatualizado na prática cotidiana na família e grupo de pares.

Em função do processo social de construção da identidade de gênero, homens e mulheres adquirem orientações diferenciadas para viverem seus papéis, 
o que realimenta o mito do amor materno e dificulta um envolvimento mais íntimo do pai com seus filhos.

No plano das representaçōes e da vivência cotidiana, a família é o espaço privilegiado de afetos, que incluem relacionamentos intimos, expressão de emoções $e$ sentimentos. No entanto, a manifestação de afetos fica subordinada às representações acerca da identidade de gênero e ao papel de cada um de seus componentes, o que tende a dificultar a expressão da afetividade paterna (Romanelli, 1995, p. 9).

As análises dos autores citados sugerem que meninos e meninas chegam à adolescência com uma orientação interpessoal e gama de experiências sociais bastante diferenciadas quando entram em um processo intenso de busca de autonomia pessoal e de individuação.

\section{Adolescência}

De acordo com diferentes autores, a adolescência pode ser caracterizada como um período de transição entre a infância e o estado adulto, cuja duração é variável em diferentes sociedades.

Becker (1987) afirma que a adolescência seria melhor explicada se entendida como a passagem que acarreta a mudança de atitude do indivíduo de simples espectador para uma postura mais ativa e questionadora. Ela é um período de revisão, de autocrítica e de transformação, sendo de vital importância para o desenvolvimento da personalidade do adolescente. Por isso, a adolescência pode ser descrita como um processo durante o qual o indivíduo amadurece e, em busca de sua individuação, vai constituindo sua identidade (Coleman, 1979).

Nas sociedades primitivas, em que há relativa homogeneidade cultural, a transição do papel de criança para o de adulto ocorre de forma gradual, num processo de amadurecimento é contínuo. Aos poucos, atribuem-se à criança funções e direitos específicos, de acordo com sua capacidade física e emocional, até que atinja plenamente a condição de adulto, ou seja, as exigências que recaem sobre este são uma continuação do que já the era pedido quando mais novo (Benedict, 1965).
Esse tipo de orientação socializadora faz desaparecer características do que é denominado crise da adolescência. Benedict (1965), que estudou as continuidades e descontinuidades do condicionamento cultural, mostra que um fato marcante na geração de conflitos para $o$ adolescente das sociedades ocidentais é a descontinuidade entre os papéis infantil e adulto, pois nelas há uma diferença muito grande entre os dois, o que obriga $o$ adolescente a desaprender as normas de conduta infantis e a assumir um comportamento diferente, de acordo com seu novo papel.

Ao mesmo tempo, como nas sociedades ocidentais a desigualdade social convive com a diversidade cultural, a adolescência torna-se um processo que é vivido conforme a inserção em uma camada social e de acordo com as orientações culturais próprias dela.

$\mathrm{Na}$ sociedade brasileira contemporânea, que passa por intenso processo de transformação, o adolescente encontra-se imerso em uma cultura na qual valores tradicionais convivem lado a lado com idéias renovadoras. A rapidez com que essas mudanças têm ocorrido contribui para dificultar o processo de amadurecimento.

Erikson (1976) considera que a principal tarefa do adolescente é a aquisição de uma identidade. Para esse autor, ele precisa se diferenciar de seus pais, divergir deles para conseguir construir os contornos de sua individualidade. A partir do momento em que entra em contato com os defeitos, os erros e as fraquezas deles, tem dificuldade em aceitá-los e em se submeter à sua autoridade. É quando o adolescente passa a agredir e a desvalorizar os progenitores e procura comportamento para conquistar sua individuação (Coleman, 1979).

Para Aberastury (1981), os pais e os adultos em geral enfrentam dificuldade para aceitar o crescimento do adolescente e estabelecer uma nova relação com ele. Os pais também vivenciam um processo de luto pela perda do corpo infantil do filho, da criança que ele deixou de ser e pelo fim da dependência completa. A transformação progressiva do filho em adulto traz a evidência de seu envelhecimento e a proximidade da morte. Eles comparam seus avanços crescentes com a fase da existência em que se encontram, fazem um balanço 


\section{Geraldo Romanelli}

de suas próprias conquistas e fracassos.

Ocorre uma simultaneidade entre a crise do adolescente e a de seus pais, quando estes sentem que estão perdendo o poder sobre os filhos e passam a utilizar diversos meios de coação, como o controle financeiro de gastos pessoais e a restrição à liberdade. Quanto a esta, Aberastury (1981) mostra que o adolescente almeja liberdade em três campos: para sair e para retornar à casa de acordo com seus anseios e necessidades; para defender uma ideologia; para viver um amor e escolher uma profissão. Os pais ocupam-se especialmente em regular os horários dos filhos, mas isto significa também conter outras formas de liberdade desejadas pelos adolescentes.

Em meio à vivência de fortes conflitos, procura de independência e autonomia, os adolescentes buscam modelos de identificação. No presente, eles tendem a desvalorizar a experiência da geração anterior, pois o que serviu para orientar a conduta de seus pais geralmente é considerado inadequado como referencial para organizar sua existência devido à velocidade de mudança dos padrões culturais (Santos,1990).

É nesse contexto que as personalidades do mundo dos espetáculos, dos esportes e das artes, cujo modo de vida é divulgado pela mídia, bem como o grupo de pares, tendem a ser tomados como modelos de conduta.

É necessário avaliar, entâo, como os adolescentes incorporam e reelaboram, na sua vivência cotidiana, representações acerca do que consideram modelos adequados de conduta.

Representações são entendidas como sistemas simbólicos de idéias e valores que orientam e dão sentido a diferentes formas de sociabilidade (Geertz, 1978). O conceito de sociabilidade é utilizado a partir da análise de Simmel (1983), como uma forma lúdica de associação e interação, e, nos adolescentes, ela encontra no grupo de pares, um espaço privilegiado para se expressar.

\section{O Grupo de Pares}

O grupo de pares (turma do colégio, da rua, do bairro, do shopping, do clube etc.) surge como um referencial fundamental para o exercício da sociabilidade dos adolescentes e como espaço de transmissão de representações diversas, fazendo com que a experiência dos pais seja preterida em relação à dos iguais (Santos, 1990).

Deve-se levar em consideração, como ressalta Salmon (1979), o grau em que os adolescentes estão segregados do mundo adulto e a importância que o grupo de pares assume nesse contexto de exclusão. A grande uniformidade de comportamentos, pensamentos e hábitos observada no grupo de adolescentes faz com que cada um deles sirva de modelo para o outro.

Assim, o grupo atua como normalizador dos comportamentos de seus membros e é também agente repressor que se impõe a cada um, levando a acatar as normas grupais face à dificuldade em ser independente, e à dor diante da possibilidade ser rejeitado pelos pares (Suplicy, 1990).

A importância que um adolescente tem para o outro parece estar associada ao fato de que a relativa igualdade de poder existente no relacionamento entre pares pode facilitar o desenvolvimento de estratégias sociais que, segundo Salmon (1979), nunca seriam aprendidas nas relações com adultos, devido à marcante desigualdade existente entre estes e os imaturos.

A importância dos grupos de pares no desenvolvimento do adolescente foi analisada por Salmon (1979) que identificou aí três funçŏes: intimidade, validação consensual e campo de referência.

A idéia de intimidade já aparece em Erikson (1976) e está relacionada d̀ experiência íntima com os pares que é considerada essencial para o indivíduo superar sua insegurança pessoal.

A validação por consenso refere-se à aprovação, por parte do grupo, das tentativas do indivíduo em estabelecer uma identidade social viável. A literatura sobre o tema mostra que, para as meninas, a importância do grupo de pares deve-se principalmente ao fato de ele constituir um espaço de intimidade em que trocam confidências. Já para os adolescentes do sexo masculino o grupo de pares tem como função principal validar consensualmente a conduta de cada um de seus membros. Nesse sentido, Salmon (1979) ressalta a importância de se levar em conta que para os adolescentes das camadas médias é difícil poder observar 0 comportamento masculino adulto nos contextos de trabalho e de lazer. 


\section{Adolecentes de Sexo Feminino 61}

Então, é dentro das relações entre pares que os meninos podem experimentar ser homem. $\mathrm{O}$ grupo de iguais provê o necessário suporte social de modelos que são buscados para definir o papel de gênero. Como as meninas têm contato mais intenso com o feminino em decorrência da maior permanência da mãe no ambiente familiar, não necessitam transferir essa função para o grupo de pares.

A função de campo de referência atribuída ao grupo de pares significa que este serve como fonte de informação para os adolescentes, inclusive sobre fatos da reprodução humana e da prática sexual.

Há uma diferença marcante no lugar que o grupo ocupa para os dois gêneros. Os assuntos que entretêm os adolescentes do sexo masculino são o desempenho e as conquistas. Nada é dito sobre erros, dúvidas ou expectativas, pois sentem dificuldade em falar de seus problemas e expor medos e dúvidas. Eles não exteriorizam seus conflitos com a mesma facilidade que as adolescentes, pois essa postura significaria entrar em confronto com o modelo de identidade masculina. Não falam de paquera, namoro e amor, falam de conquistas e transas. Já o grupo de adolescentes do sexo feminino aborda temas como namoro, paquera, amor, sofrimento, perda, partilhando dúvidas, temores e expectativas (Suplicy, 1990).

\section{A Relação com os Pais}

$\mathrm{Na}$ sociedade ocidental, as adolescentes tendem a ser mais protegidas e preservadas com respeito ao mundo exterior do que os rapazes. Essa característica reflete e, ao mesmo tempo, reforça estereótipos veiculados pela cultura que valoriza e estimula a imagem da mulher frágil e desamparada, reiterando que sua esfera natural e segura é o locus familiar.

No entanto, uma série de mudanças sociais significativas que vêm ocorrendo na sociedade brasileira, entre elas a exaltação da individualidade e a reivindicação mais acentuada da liberdade feminina, afetando a representação existente sobre a mulher. Assim, as mães que viveram esse processo de transformação são levadas a socializar suas filhas em moldes diferentes daqueles em que foram educadas, o que tornou necessária a busca de novas estratégias para a transmissão de valores. Ordens inquestionáveis e autoritárias passaram a não ser mais aceitas pelas adolescentes. Nesse sentido, ocorreu a valorização do chamado "diálogo" entre pais e filhos. Todos esses fatores são indicativos de mudanças na distribuição de poder dentro do campo das relações familiares e também na esfera pública.

E provável que para as mães o estabelecimento desse clima de diálogo seja a forma que encontram de influir e, concomitantemente, exercer vigilância sobre as filhas. Essa proximidade dá oportunidade para que elas se coloquem a par do que se passa e pensa nos grupos em que suas filhas convivem. Em famílias de camadas médias, que adotam padrões de conduta mais flexíveis, o exercício ostensivo da autoridade parental torna-se difícil de ser mantido e é só através de conversas e de uma postura de intimidade e igualdade que o código de valores pode ser transmitido.

O diálogo, a troca de idéias, as confidências são tentativas, tanto por parte das mães, quanto das filhas de influenciar o outro, de passar valores. Então, enquanto a mãe busca uma forma de exercer poder sobre a vida da filha, esta tenta criar um espaço mais democrático, em que possa expressar suas vontades e ter direito a influir na tomada de decisões que afetam sua vida (Brioshi \& Trigo, 1989).

No discurso das adolescentes de camadas médias aparece o desejo de estudar e trabalhar e ausência de pressa para casar, parecendo estarem imbuídas de uma nova representação de mulher e de um novo papel a ser desempenhado pelo sexo feminino na sociedade.

Em sua maioria, as escolhas profissionais recaem sobre tarefas consideradas femininas como as atividades paramédicas. Isso faz pensar numa transposição para a esfera profissional da premissa que fundamenta e estrutura a função da mulher no campo familiar: ajudar o outro e dedicar-se a ele, o que é condizente com as análises de Chodorow (1979).

A escolarização superior, essencial para uma futura profissionalização, é incentivada pelos pais e resulta da avaliação que eles fazem acerca do trabalho de suas filhas, que é visto como um potencial a ser acionado em caso de necessidade, seja pelo fim do casamento, seja em eventuais dificuldades financeiras do marido (Romanelli, 1986).

Por sua vez, a postura de retardar o casamento 


\section{Geraldo Romanelli}

está associada a maior liberdade de que desfrutam atualmente e que possibilita manterem relações sexuais pré-maritais.

\section{Metodologia}

A pesquisa foi realizada com dez adolescentes do sexo feminino das camadas médias. Nove entrevistadas tinham dezessete anos na época da pesquisa e uma delas iria completar essa idade dentro de quatro meses. Todas eram alunas de uma escola particular situada em Ribeirão Preto-SP e cursavam o terceiro ano do ensino médio.

A coleta de dados foi realizada através de entrevistas gravadas, orientadas por um roteiro semiestruturado, posteriormente transcritas na íntegra, realizadas na casa das adolescentes em ambiente que garantisse a privacidade da coleta dos dados. A duração média das entrevistas foi de uma hora e dez minutos.

Para assegurar o anonimato os nomes com que são indicadas neste trabalho foram alterados.

\section{Análise dos Dados}

\section{As relações com a familia}

Inicialmente procura-se caracterizar as famílias das adolescentes, na tentativa de melhor configurar os aspectos de sua vivêrcia doméstica, bem como as condições em que foram socializadas.

Em relação à idade dos pais, alguns encontram-se na faixa etária entre 40 e 50 anos. Os pais de Carla têm 63 e 56 anos; as mães de Geórgia, de Érika e de Juliana estão na faixa entre 37 e 38. anos e o pai de Bruna e Helena com 52 e 54 anos respectivamente.

As famílias são pouco numerosas, com três filhos em média e dois casais - os pais de Juliana e de Geórgia - são separados.

No que se refere à escolaridade do pai, cinco concluíram o curso superior, quatro o ensino médio e outro tem ensino médio incompleto. Quanto às mães, cinco completaram o ensino superior, uma o ensino médio, duas o ensino fundamental, uma tem ensino médio incompleto, e outra não terminou o ensino fundamental. $O$ grau de escolaridade de marido e esposa tende a ser semelhante; quando isso não ocorre ele tem escolaridade um pouco mais elevada do que a esposa. A única exceção é a mãe de Carla, com nível superior completo, enquanto o marido tem apenas o secundário.

Entre as ocupações do pai das adolescentes, cinco exercem atividades ligadas ao comércio; dois são profissionais liberais, três ocupam cargos de chefia em empresas e um é fazendeiro.

A quase totalidade das mães não tem atividade profissional e rendimentos próprios, dedicando-se principalmente aos cuidados com a casa e filhos. Apenas a mãe de Érika tem rendimento proveniente de sua ocupação como enfermeira. As outras que exercem atividades extra-domésticas auxiliam os maridos comerciantes. Além dessas, a mãe de Juliana trabalha em uma loja de bebidas, a mãe de Geórgia montou recentemente uma empresa de assessoria, depois que se separou do marido. De qualquer modo, nenhuma dessas mulheres - exceto a mãe de Érika - aufere rendimentos no exercício dessas atividades.

Embora os dados coletados não permitam estabelecer com precisão a renda familiar, a ocupação dos pais, a moradia $\mathrm{e}$ o estilo de vida das adolescentes indicam que os recursos financeiros são elevados.

Examinando-se as relações dessas adolescentes com o pai e com a mãe, observam-se diferenças na forma como se relacionam com cada um deles. A maior parte diz conviver melhor com o pai. É possível que a permanência das mães no contexto doméstico, tendo em vista que se dedicam principalmente ao cuidados com os filhos e à administração da casa, produza mais zonas de conflito, como aparece nas falas abaixo:

(...) eu convivo mais com a minha mãe, entendeu, tipo dia e noite, e meu pai eu só vejo a noite, então a gente... é mais dificil eu brigar com ele, é muito difícil eu pedir uma coisa pra ele e ele não me dar, entendeu. Ela já é mais exigente, bem mais que ele. Eu acho que eu me dou melhor com ele. (Carla)

(...) Ele passava mais tempo fora que dentro de casa. Então eu não tinha... O tempo que eu tinha com ele eu queria aproveitar, não tinha tempo pra brigar. (Geórgia) 
De modo geral, as mães tendem a exercer maior controle sobre as filhas. Essa constatação coincide com a análise de Chodorow (1979) que mostra como elas tentam manter a indiferenciação e a dependência, dificultando seu processo de individuação e de amadurecimento.

Uma das formas é estabelecer horários para chegar em casa à noite, o que acarreta sérios conflitos e longas discussões, principalmente no início da adolescência. Fernanda relata que sua mãe espera-a até tarde quando sai à noite. Essa postura de tentar controlar e limitar o lazer noturno parece incomodála imensamente. Ela diz discutir muito porque não aceita passivamente as restrições da mãe a sua liberdade e que se relaciona melhor com o pai.

No discurso das adolescentes é marcante a valorização do diálogo, o que significa uma tentativa de negociar com os pais um espaço de maior liberdade, como se nota na fala de Fernanda:

Ai, ela (mãe) proíbe muitas coisas e eu sempre debato.

Segundo Brioschi \& Trigo (1989), como o exercício ostensivo da autoridade parental é mais difícil atualmente, o controle sobre as filhas pode acontecer através de conversas e de uma postura de intimidade e igualdade. A maior proximidade na relação mãe-fiíha abre possibilidades para que elas se coloquem a par do que acontece com as filhas e dos valores predominantes no grupo de pares. Dessa forma, o diálogo é um recurso de que lançam mão para exercer uma vigilância sutil, ao mesmo tempo em que tentam influenciar.

A minha mãe era diferente (...) tinha aquele jeito de conversar, não mandando, sabe, mas de um jeito amigo.(...) Eu acho que com mãe, mulher é diferente também, né. (...) não é aquele jeito de mandar 'porque eu quero', explica o por que das coisas. (Érika)

Essas adolescentes conversam com os pais predominantemente sobre questões do dia-a-dia. Com o genitor falam sobre notas, escola, futuro. Com as mães, dos amigos, das brigas e dos relacionamentos com namorados e garotos com quem ficam. Apesar de algumas discutirem esses assuntos, fica patente que a mãe não é a interlocutora preferida, principalmente quando se trata de namoro e, especialmente, de ficar.

$E$ interessante atentar para o fato de que essas adolescentes afirmam não conversarem com o pai sobre namorar, ficar e as dificuldades que envolvem essas formas de relacionamento. Para elas, ele não assume o papel que é habitualmente da mãe, referido à dimensão afetiva da vida doméstica.

A maior parte das adolescentes afirma que não toca em certos assuntos com os pais, pois considera que isso poderia deixá-los muito preocupados, o que indica, na percepção das filhas, que eles estão desatualizados e incapacitados para auxiliá-las na resolução dos problemas que fazem parte de suas vivências cotidianas, principalmente quanto ao relacionamento entre os sexos, pontuando diferenças entre seu código moral e o dos genitores. A disparidade entre os conhecimentos transmitidos pelos pais e as vivências das entrevistadas resulta da rápida transformação da sociedade que exige por parte dos jovens novas respostas e novos comportamentos (Santos, 1990).

As adolescentes, em sua maioria, afirmam que os pais deram a elas orientações a respeito de sexo. Elas relatam que as informações foram transmitidas principalmente através de advertências acerca dos riscos que uma vida sexual ativa impõe, como gravidez indesejada e doenças sexualmente transmissíveis. Fica implícito nas recomendações parentais o desejo de que as filhas não iniciem vida sexual precocemente e que procurem conhecer bem o parceiro antes de qualquer envolvimento.

Meu pai já diz assim: 'Você sabe o que os homens pensam, né. Você sabe o que o menino quer fazer, né.'A minha mãe já fala: Ai, meu Deus.' Ela não quer saber de nada disso. (Bruna)

Não me orientou no sentido de quando eu transar usar anticoncepcional, me orientou no sentido de não transar. (Iara)

O controle pode remeter à dificuldade dos pais em aceitarem o fato de suas filhas estarem se 


\section{Geraldo Romanelli}

preparando para uma vida independente, como afirma Aberastury (1981).

\section{Estudo e projeto de profissionalização}

A importância atribuída aos estudos e aos projetos de profissionalização na vida dessas adolescentes está associada a representações sobre o papel social da mulher e possibilita compreender alguns aspectos de suas identidades de gênero.

Em suas falas, as adolescentes revelam o desejo de estudar, de ter uma carreira, de trabalhar e de se casar somente após a conclusão do curso superior. Nesse sentido, elas parecem ter uma nova representação do papel da mulher na sociedade. $O$ exame mais cuidadoso de seu discurso indica que continua muito pregnante a ambivalência sobre qual seria seu lugar na esfera pública.

A maioria das entrevistadas dedica entre uma hora e meia a três horas diárias aos estudos e declara que dorme pelo menos duas horas todas as tardes. Esse comportamento possibilita caracterizar uma relativa despreocupação com o vestibular, tendo em vista que todas são alunas do terceiro colegial e apenas duas - Erika e Iara - voltam-se integralmente às tarefas escolares, declarando que não têm nenhuma hora de folga, pois estudam por volta de nove horas todos os dias, inclusive nos finais de semana. Apesar da relativa uniformidade nas condições financeiras das famílias, percebem-se algumas diferenças no poder aquisitivo dos pais, o que acaba repercutindo no modo como as entrevistadas encaram o ingresso na universidade e a possibilidade de uma formação de nível superior.

Nesse sentido, entende-se porque Iara dedica-se mais do que a maioria aos estudos. Os pais pagam para ela uma escola particular, enquanto sua irmã mais nova estuda em uma pública. Outro indício da situação financeira familiar é que ela é a única que não mora em bairro nobre e o aspecto geral da casa é bem menos sofisticado do que das demais residências. Esses dados possibilitam levantar a hipótese de que a conquista de um diploma de ensino superior é importante para Iara iniciar uma carreira profissional e tornar-se financeiramente independente. $O$ fato de a maioria ter mães que não exercem atividade profissional pode estar contribuindo para a despreocupação quanto ao futuro profissional, já que ao se identificarem com sua genitora também o fazem em relação a seus valores. Ou seja, suas mães demonstram no contexto familiar, onde ocupam papel de destaque como donas-de-casa, que este é o locus privilegiado da mulher.

Chodorow (1979) ressalta que na sociedade ocidental as meninas vão à escola para se prepararem para a vida num meio tecnológico e complexa. Contudo, ressalta que paira a impressão de um pseudo-treino, já que a aprendizagem escolar não deve comprometer a orientação muito mais importante, realizada sobretudo em âmbito doméstico, que consiste em dotar as meninas da qualidade feminina, a fim de poderem exercer adequadamente os papéis de esposa e mãe.

A ambivalência em considerar os estudos como meio de aprendizado profissional ou como atividade que se esgota em si mesma, como foi observado por Salem (1980), aparece no discurso dessas adolescentes. Essa ambigüidade faz pensar nas expectativas com respeito à carreira profissional futura e deixa transparecer a suposição de que serão sustentadas por seus maridos.

Assim, por um lado, o curso superior é visto como meio para aprimoramento pessoal, como aparece na fala de Carla:

Pra mim ter uma educação, uma formação boa, pra mim crescer psicologicamente, sabe, a cabeça, tudo, pra mim ser mais informada, vamos dizer assim.

A valorização de uma formação de nível superior, em detrimento do seu papel econômico, encontra sustentação dentro do próprio contexto familiar, já que há mães das entrevistadas nesta situação e que não exercem nenhuma atividade remunerada.

No entanto, o inverso ocorre com Érika, uma das que mais se dedica aos estudos, cuja mãe é a única que tem atividade profissional e rendimentos próprios e que atribui grande valor ao trabalho extradoméstico; neste caso, o desejo de exercer uma atividade remunerada pode ser associado a sua identificação com a mãe.

Por outro lado, depreende-se do discurso dessas adolescentes que suas famílias valorizam a carreira universitária como forma de preparação para 
a vida e a profissão como potencial a ser acionado em caso de necessidade, como o fim do casamento, ou em outras situações que possam ocasionar crise financeira na família.

E nesse sentido que:

$O$ investimento na escolarização das filhas como base para o exercício de uma profissão compensadora pode também ser entendido como uma luta silenciosa e sutil para promover mudanças nas regras que regem as relações internar no âmbito familiar (Salem, 1980, p. 87).

Por isso, a conclusão de um curso superior aparece como elemento importante para não reproduzir integralmente a dependência financeira de suas mães.

Minha mãe, como ela não terminou, e ela é dependente do meu pai, ela acha importante não ficar dependendo. (...) Ah, porque eu acho que pra mim ser independente eu preciso ter um curso superior, entendeu. Pra mim conseguir o nivel de vida que eu quero, entendeu. (...) Eu acho conveniente eu me casar depois que eu estiver estabelecida na minha profissão, entendeu: uns vinte e cinco assim. (Juliana)

Eu não quero me casar no meio do caminho. Depois que eu estiver pronta, em algum lugar, com a minha vida tudo certinho, daí eu caso. (Geórgia)

A maioria das escolhas profissionais recai sobre carreiras vistas como femininas, como as atividades paramédicas. $O$ fato de o curso de Psicologia ser o mais mencionado indica uma grande preocupação com sentimentos e com relacionamentos, o que coincide com a análise de Gilligan (s/d) que mostra a importância da atuação feminina na constituição de teias de relacionamentos.

Porque eu gosto de mexer com gente, tipo Psicologia também. (Ana Paula)

Embora predominante, essa postura de ajudar o outro não é única. Débora e Bruna distanciam-se desse modelo, pois se referem claramente à profissão como um instrumento que possibilita prover o próprio sustento. Elas também se diferenciam por não justificarem a escolha profissional pelo prazer em ajudar os outros ou por lidar com pessoas, não assumindo a posição de "ser para o outro", como aparece na fala de Débora:

Meu pai não vai continuar me sustentando a vida inteira. (...) mas acho que estudo é pra isso: pra você chegar... sobreviver, pra você ter com o que ganhar dinheiro, eu acho.

Por outro lado, as mães não preparam as filhas para aprenderem serviços domésticos, nem exigem que elas as ajudem nesses afazeres, com exceção da mãe de Débora.

\section{A sociabilidade no grupo de pares}

É dentro de um contexto social de intensas transformações que o grupo de pares, espaço de intimidade (Salmon, 1979), surge como referência fundamental para organizar a conduta dessas adolescentes, já que há uma disparidade entre os conhecimentos aprendidos no convívio com os pais e suas formas de sociabilidade.

Aí, no seu interior, trocam confidências e vivenciam suas emoções e dificuldades e onde abordam temas como namoro, ficar, paqu, amor, sofrimento, perda, como se depreende da fala de Bruna:

Elas (as amigas) parecem que entendem mais por viverem quase as mesmas coisas, né. Tipo de coisa, não a mesma coisa. Elas entendem mais (...). Elas sabem melhor do que os meninos. Escola não é muito problema, mais é menino, amiga, briguinha de amiga, essas coisinhas mais... conversa com elas. É desse tipo de conversa mesmo (brigas com o namorado, com o rapaz com quem tá ficando), o que que elas pensam, se acha que deve ir atrás, se não. Essas coisas. (...) Você fica: 'Ai, fiquei com tal'. Conta como foi. 'Ai, tô namorando', conta como começou.

Meninos e meninas, segundo Chodorow (1979), chegariam à puberdade com uma orientação 


\section{Geraldo Romanelli}

interpessoal diferente, devido ao relacionamento específico com a mãe no início da infância, a formação da identidade feminina, o vínculo de apego muito íntimo que possibilita o desenvolvimento da empatia e da sensibilidade no relacionamento com o outro. Nesse sentido, as meninas mostram grande sensibilidade $\mathrm{e}$ preocupação pelos sentimentos dos outros, o que não acontece com os meninos. Essa diferença está presente no discurso das adolescentes quando se referem à dificuldade de conversar sobre seus sentimentos com os meninos e afirmam que é melhor conversar com amigas por ser mais fácil estabelecer uma relação empática.

Problema de menina é problema de menina, os garotos não tem isso, (eles não) sentem $o$ que a gente sente. (Ana Paula)

A relação de intimidade é vivenciada por essas adolescentes como algo relativamente exclusivo, que ocorre com poucos escolhidos. Elas saem juntas, conversam sobre meninos e namorados nos grupos maiores, mas não fazem confidências a todas as adolescentes do seu círculo de amizades. Em geral formam uma díade com a melhor amiga ou compõem um grupo com mais duas com as quais trocam confidências (Salmon, 1979).

Há uma preocupação por parte dessas adolescentes em não dividir suas experiências mais intimas com qualquer amiga, pois consideraram que as mulheres conversam muito sobre relacionamentos e emoções e acabam não guardando sigilo sobre o que lhes é confidenciado.

A minha melhor amiga é mulher. Ah! Mas eu acho que homem... não sei eu confio mais em menino. (...) Não sei, acho que ele não é tão aberto. Não sai falando, sabe. Acho que menino guarda mais. Ele nem tem pra quem contar. (Ana Paula)

O grupo de pares é um espaço favorável à criação de uma rede de sociabilidade marcada pela livre expressão de emoções e sentimentos vistos por essas adolescentes como exclusivamente femininos. Porém, o contato com outras mulheres que não pertencem ao grupo é percebido como sendo pautado pela competição e disputa.
Porque eu já tenho... cê tem a panelinha das cinco menininhas e tal que fica. Quando você vai sentar em outro lugar, a menina que não vai conversar com você. Ela já tem a turma dela. (...) elas ficam assim: "Aquela menina é metida", então não se dão nem ao trabalho de conhecer. Tem disputa. (Bruna)

As conversas e discussões que ocorrem no interior do grupo geram um campo de referência (Salmon, 1979), isto é, um conjunto de informações que tende a orientar a conduta de seus componentes.

Além disso, o grupo atua para normatizar comportamentos, desempenhando a função de validação por consenso o que corresponde à aprovação nele de condutas individuais. Bastante elucidativo a esse respeito é o fato de as adolescentes se vestirem de forma extremamente semelhante, chegando até mesmo a estabelecer um padrão, como roupas e sapatos de determinadas marcas, que são as mesmas para a maioria delas, indicando a submissão às suas normas e o receio de serem rejeitadas pelos pares.

Ainda mais do jeito que a gente tá hoje. Se você chega com uma roupa que não é de marca, que não é da moda, as pessoas já te olham meio assim: 'ai, cafona, brega'. Então acho que você usa mais para agradar os outros, entendeu. (...) De repente se eu vir uma coisa que eu gostar, eu compro. Só que a gente fica assim meia com receio de usar. (Helena)

\section{As relações afetivas: namorar e ficar}

Nenhuma das adolescentes estava namorando quando as entrevistas foram realizadas. Três tiveram relações de namoro que duraram mais de um ano, enquanto os das demais foram mais curtos, variando entre uma semana e dez meses.

Em suas representações, o namoro está associado à certeza de que um gosta mesmo do outro e à idéia de compromisso, implicando em assumir responsabilidade em relação a uma outra pessỏa; há uma certeza maior de que se está junto e que se pode contar com essa pessoa, sendo esta a noção que diferencia namorar de ficar. 


\section{Adolecentes de Sexo Feminino 67}

O namoro é considerado uma relação de intimidade e de amizade entre parceiros, na qual há uma troca intensa de afeto e experiência, sendo a exclusividade uma característica sua, vista como fator que promove o amadurecimento e possibilita aprender com o outro.

(...) namorar requer mais intimidade. Além de seu namorado, ele é teu amigo, sabe tudo que acontece com você. Você cobra mais da pessoa. (...) namorar já é mais... requer mais responsabilidade. (Juliana)

No entanto, a maioria das adolescentes aponta a restrição da liberdade e a perda da privacidade imposta pelo compromisso assumido como fator negativo da relação de namoro, constituindo uma perda. Algumas ressaltam a ịdéia de que são jovens e devem aproveitar a vida; consideram-se muito novas para a questão da exclusividade exigida pelo namoro, preferindo apenas ficar. Elas se justificam dizendo é melhor permanecerem sozinhas até acharem alguém de quem realmente gostem. Além disso, algumas se ressentem pelo fato de o namoro acarretar a redução, ou mesmo perda, do contato com as amigas.

(...) Eu acho também que você vai se afastando das pessoas, das amigas. Você sai só com o namorado, seu namorado não gosta de sair, e você não sai pra onde as suas amigas vão realmente. (Juliana)

A representação sobre ficar está associada a uma relação em que não há compromisso. A duração temporal do vínculo afetivo não parece ser um elemento crucial nessa distinção, já que duas entrevistadas afirmam terem ficado com um parceiro por mais de seis meses, mas que, nesse caso, há a possibilidade de viver bons momentos com alguém com quem não se tem compromisso.

É um namoro sem compromisso por algum tempo, por algumas horas, só por

uma hora, certo, sem compromisso. Sei lá, é dar uns beijinhos, uns abraços, certo, conversar um pouquinho ... namorar sem compromisso um dia só. (Iara)

De acordo com o que se pode apreender da fala dessas adolescentes, o comportamento de ficar é visto como uma forma de conhecer, de experimentar. S6 ficando é que elas podem saber se realmente gostam e se querem ter uma relação mais séria com o garoto; seria uma forma de buscar alguém com quem se quer estabelecer um namoro, portanto um primeiro passo, um pré-requisito.

$O$ ponto negativo em ficar, levantado pela maioria, é que a garota pode passar a ser vista como vulgar, "ficar mal falada".

Quando uma menina só fica é chamada de galinha. (Ana Paula)

É importante ressaltar que convivem lado a lado duas maneiras de vivenciar a relação de ficar. Em alguns momentos isto é referido como uma forma de curtição em que se passa momentos agradáveis com uma pessoa, conhecida ou não. Em outros, ficar aparece como requisito para iniciar o namoro.

\section{Considerações Finais}

Nas famílias de camadas médias o relacionamento parental com as filhas e, principalmente, entre mães e filhas passa por alterações e, dependendo das circunstâncias, pode ser pautado pelo diálogo, o que não exclui a imposição de ordens por parte dos pais.

A velocidade na mudança de valores e padrões culturais contribui para que as adolescentes tenham posturas ambíguas sobre a posição da mulher tanto na esfera privada, quanto no domínio público. Assim, oscilam entre assumir condutas tradicionais nas relações domésticas, o que as aproxima de suas mães ou a incorporar comportamentos inovadores, em busca de autonomia pessoal, de realização profissional e independência financeira.

Como a experiência dos pais não é mais suficiente para dar respostas satisfatórias a suas indagações, nem para oferecer orientações à vida social em processo de mudança, o grupo de pares emerge como espaço privilegiado em que podem expor suas dúvidas, expectativas e aspirações em busca de informações e referências sancionadas pelos iguais e que, muitas vezes, se contrapõem às prescrições parentais.

Uma dimensão da existência das adolescentes onde as ambigüidades aparecem de forma bastante viva está no contraste entre namorar e ficar, que 


\section{Geraldo Romanelli}

pode ser exemplificada pelos relacionamentos afetivos de Juliana e de Iara. A primeira com uma relação de oito meses com um mesmo rapaz a quem não considerava namorado, o que a levou a ficar com outro e a que o rapaz, sentindo-se traído romper o relacionamento. Já Iara, que mal se encontrava com o rapaz com quem teve um relacionamento de dois meses, sabia que ele tinha outra parceira e ela mesma ficou com outros. Ainda assim, afirma que namorava o rapaz.

As explicações oferecidas indicam que cada situação tem um significado atribuído por quem vivencia um determinado relacionamento afetivo e que a fronteira entre ficar e namorar é muito mais tênue e indefinida do que as próprias adolescentes admitem

De qualquer modo, tanto a conduta dos pais, quanto a das filhas está envolvida por ambigüidades que contribuem para ampliar o espaço de liberdade das adolescentes, reduzindo a influência parental, mas que também criam situações de incerteza e de indeterminações quanto aos limites do que elas podem fazer.

\section{Referências Bibliográficas}

Aberastury, A. (1981). O adolescente e a liberdade. In: A. Aberastury \& M.Knobel (orgs.). Adolescência Normal. Porto Alegre: Artes Médicas.

Becker, D. (1987). O que é adolescência. São Paulo: Brasiliense.

Benedict, R. (1965). Continuidades e descontinuidades no Condicionamento Cultural. In: C. Kluckhohn et alii.(Org.), Personalidade na natureza, na sociedade e na cultura. Belo Horizonte: Itatiaia.

Brioschi, L.R. \& Trigo, M.H.B. (1989). Família: Representação e Cotidiano. Reflexão sobre um trabalho de campo. São Paulo: Textos CERU 1.

Chodorow, N. (1979). Estrutura familiar e personalidade feminina. In: M.Z. Rosaldo \& L. Lamphere (orgs.), A mulher, a cultur, a sociedade. Rio de Janeiro: Paz e Terra.
Coleman, J.C. (1979). Current views of the adolescent process. In: J.C. Coleman (org.), The school years. Current issues in the socialization of young people. London: Methuen.

Conceição, I.S. (1990). Relações interpessoais entre adolescentes e profissionais. In: S. Arruda \& S. Cavasin (orgs), Sexualidade na Adolescência: Educação e Midia. ECOS.

Erikson, E. (1976). Identidade, juventude e crise. Rio de Janeiro: Zahar.

Geertz, C. (1978). A interpretação das culturas. Rio de Janeiro: Zahar.

Gilligan, C. (s/d) Uma voz diferente. Rio de Janeiro: Rosa dos Tempos.

Romanelli, G. (1986). Famílias de camadas médias: a trajetória da modernidade. São Paulo, tese de doutorado. FFLCH/USP.

Romanelli, G. (1995). Autoridade e poder na família. In: M.C.B. Carvalho (org.), A familia contemporânea em debate. São Paulo: Cortez/ EDUC.

Sá, C.P. de (1993). Representações Sociais: o conceito e 0 estado atual da teoria. In: M.J. Spink (org), $O$ conhecimento no cotidiano. São Paulo: Brasiliense.

Salem, T. (1980). O velho e o novo. Petrópolis: Vozes.

Salmon, P. (1979). The role of the peer group. In: J.C. Coleman (ed), The school years. London: Methuen.

Santos, L.G. dos. (1990). A mídia e as transformações na subjetividade. In: S. Arruda \& S. Cavasin (orgs), Sexualidade na adolescência: Educação e Mídia. ECOS.

Simmel, G. (1983). Sociabilidade-um exemplo de sociologia pura ou formal. In: E. Moraes Filho (org.) Simmel: sociologia. São Paulo: Ática.

Suplicy, M. (1990). Os caminhos da repressão sexual no desenvolvimento dos adolescentes. In: S. Arruda \& S. Cavasin (orgs), Sexualidade na adolescência: Educação e Mídia. ECOS 